\title{
TORTICOLLIS SECONDARY TO OCULAR PATHOLOGY
}

\author{
C. R. P. WILLIAMS， E. O'FLYNN， N. M. P. CLARKE， R. J. MORRIS \\ From Southampton University Hospital, England
}

$\mathbf{W}^{\mathrm{e}}$

e report a series of 15 children, six male and nine female, of average age 20 months, seen at a paediatric orthopaedic clinic with torticollis. Orthopaedic examination revealed a normal range of neck movement in all cases but in seven there was palpable tightness in the absence of true shortening or contracture of the sternomastoid muscle.

The patients were prospectively referred for ocular examination. In five of the $\mathbf{1 5}$ an ocular cause for the torticollis was detected with underaction of the superior oblique muscle in three, paresis of the lateral rectus muscle in one and nystagmus in one. Another two patients were found to have an abnormal ocular examination which was thought to be unrelated to their torticollis. Three of the patients with ocular torticollis required extra-ocular muscle surgery to abolish the head tilt and one of these had a tight sternomastoid muscle. Two of the non-ocular group had surgical release of the sternomastoid muscle; in the rest, the condition either resolved with physiotherapy or required no active treatment.

We recommend that all patients with torticollis and no clear orthopaedic cause are referred for ocular assessment since it is not possible clinically to distinguish ocular from non-ocular causes.

J Bone Joint Surg [Br] 1996;78-B:620-4.

Received 17 November 1995; Accepted after revision 21 February 1996

The causes of an abnormal head posture in children include skin webs, congenital muscular torticollis, deformities of the cervical spine and the craniocervical junction, ocular and neurological problems, trauma, cervical adenitis and atlanto-axial rotary instability (Kushner 1979; Lovell and

C. R. P. Williams, FRCS, Senior Registrar in Orthopaedics N. M. P. Clarke, ChM, FRCS, Consultant Orthopaedic Surgeon E. O'Flynn, DBO, Orthoptist

R. J. Morris, FRCOphth, Consultant Ophthalmic Surgeon

Southampton University Hospitals NHS Trust, Tremona Road, Shirley, Southampton SO16 6YD, UK.

Correspondence should be sent to Mr N. M. P. Clarke.

(C)1996 British Editorial Society of Bone and Joint Surgery 0301-620X/96/41241\$2.00
Winter 1986; Kahn, Davidson and Drummond 1991). The posture varies with the cause, but may include head tilt, face turn and chin elevation or depression (Fig. 1). The common 'cock-robin' posture includes a face tilt and turn to the opposite side and some chin depression (Fig. 2). The term 'torticollis' means twisted neck and is derived from the Latin words 'tortus' and 'collum' (Kahn et al 1991).

We started our review after seeing a child with torticollis but with no structural muscle contracture. Only after unsuccessful physiotherapy and manipulation under anaesthesia was she referred to an ophthalmic clinic. She was diagnosed as having a palsy of the superior oblique muscle; treatment of this resolved her abnormal head posture. Since then all cases of torticollis of unclear aetiology have been prospectively referred for ophthalmic assessment.

\section{PATIENTS AND METHODS}

From January 1993 to January 1994 all children referred to NMPC with torticollis with no obvious orthopaedic cause were referred for ophthalmic assessment. There were nine girls and six boys; all but one, a girl of 15 years, were between three months and four years of age at referral (mean 13 months). We recorded their history, examined the neck and noted any craniofacial asymmetry. Plain radiographs of the cervical spine were taken, and the teenage girl had MRI of the neck and posterior fossa of the skull.

At the ophthalmic clinic, the patients had a full examination, including assessment of extra-ocular muscle balance and binocular status, and measurement of any refractive errors. None had had any apparent ocular abnormality before referral.

\section{RESULTS}

Ocular examination. In eight children the ocular examination was normal and six of these showed plagiocephaly. Seven had abnormal ocular examinations and three of these had plagiocephaly. In two of the seven patients the ocular abnormality was not considered to contribute to the torticollis, but in the other five there was an ocular cause for the abnormal neck posture (Table I).

The patients were considered in two groups, ten with no ocular abnormalities related to their head posture, and five with an ocular cause for their torticollis (Tables II and III). The ten patients in the non-ocular group included three with congenital dislocation of the hip (CDH), one of whom had congenital vertical talus and renal tubular insufficiency, 


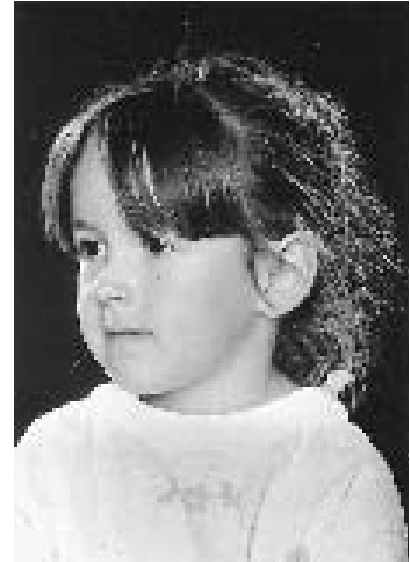

Fig. 1a

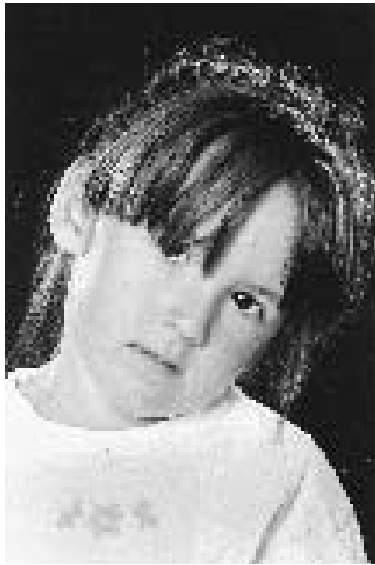

Fig. 1b

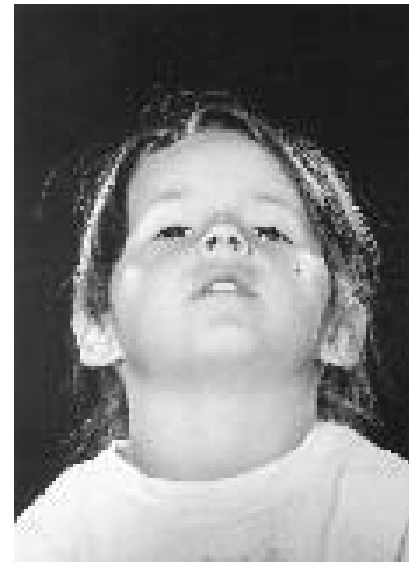

Fig. 1c

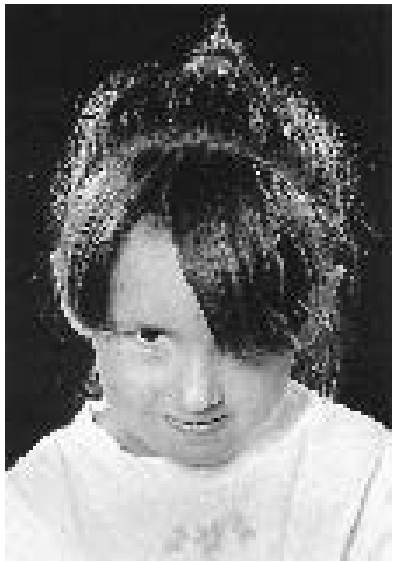

Fig. 1d

Photographs of a model to show the three components which may be involved in torticollis; a) face turn, b) head tilt, and c) chin elevation or d) depression.

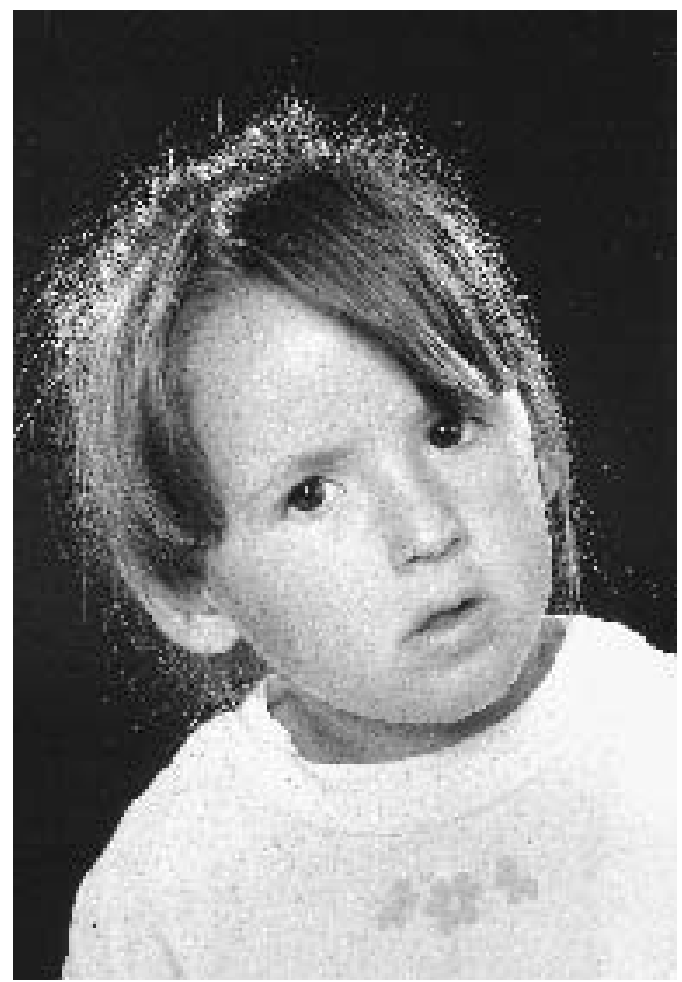

Fig. 2

Photograph of a model to show the 'cock-robin' position. There is right head tilt, left face turn and slight chin depression.

and also one with partial deletion of chromosome 10. The ocular group had no other diagnoses.

We reviewed the features of torticollis in all 15 patients to ascertain the presence of any predictive factors for an ocular origin:

Onset of abnormal posture. In the ocular group of five patients, two were noted to have had an abnormal head posture at birth and the other three at three months of age. Of the ten patients in the non-ocular group, seven had had torticollis diagnosed at birth, and one each at three months, three years and 13 years of age.

Family history of ocular problems. Eight patients in the non-ocular group had no family history of any disorder of ocular mobility and two had a history of strabismus in a second-degree relative. In the ocular group, two patients had no family history of ocular disorder, two had a firstdegree relation with a squint, and the father of the one with nystagmus was similarly affected.

Neck movement. All patients had a full symmetrical range of cervical movement (ROM), but one patient in the ocular group and five in the non-ocular group had a palpably tight sternomastoid muscle at maximal tension.

Treatment. The three ocular patients with underaction of the superior oblique muscle have all required extra-ocular muscle surgery to weaken the inferior oblique muscle of the affected eye. This has reduced the head tilt in two (Fig. 3 ), and restored binocular single vision in the patient who had ceased using an abnormal head posture. The patient with nystagmus now has a small, cosmetically acceptable variation of head posture and has not yet required ocular surgery. The child with a paresis of the sixth cranial nerve is improving spontaneously and has not required treatment.

Two patients in the non-ocular group have needed surgical release of a tight sternomastoid muscle. One had a good result but the other, the teenage girl, requires continued physiotherapy. Seven have responded to physiotherapy alone, and in two the condition has settled spontaneously.

\section{DISCUSSION}

Torticollis in infancy has various causes other than ocular pathology. These include pterygium colli, sternomastoid muscle contracture, bony abnormalities, neurological prob- 


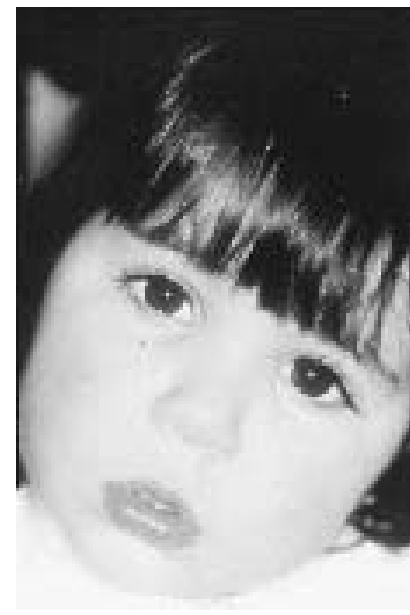

Fig. 3a

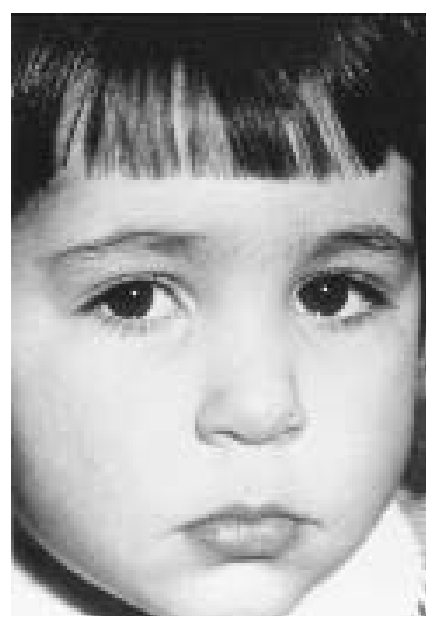

Fig. 3b
Photographs of a patient with palsy of the right superior oblique muscle, showing the head posture adopted to obtain conjugate gaze before (a) and after (b) corrective surgery.

Table I. The ocular findings in seven of the 15 patients and their relation to torticollis

\begin{tabular}{lll}
\hline & Number & $\begin{array}{l}\text { Related to } \\
\text { torticollis }\end{array}$ \\
\hline Superior oblique muscle palsy & 3 & Yes \\
Lateral rectus muscle palsy & 1 & Yes \\
Nystagmus & 1 & Yes \\
Convergent squint & 1 & No \\
Hypermetropia & 1 & No \\
\hline
\end{tabular}

lems including tumours of the posterior fossa (especially in older children), trauma including birth injuries, inflammatory conditions and idiopathic atlanto-axial rotary subluxation (Lovell and Winter 1986; Kahn et al 1991). Most of these can be diagnosed or suspected from the history, a thorough examination and plain radiographs when they are indicated. Intracranial causes can be excluded by MRI. Idiopathic atlanto-axial rotary instability may occur after an upper respiratory infection; it usually resolves quickly without treatment, but may be difficult to diagnose and require special imaging techniques (Fielding and Hawkins 1977; Phillips and Hensinger 1989).

Congenital muscular torticollis is relatively common in the first two months of life and is thought to be due to birthrelated trauma. It may be associated with $\mathrm{CDH}$ in up to $20 \%$ of cases (Hummer and MacEwen 1972; Weiner 1976). Plagiocephaly is common and there may be a palpable muscle tumour or tightness of the sternomastoid. Most cases resolve quickly with conservative treatment and physiotherapy, but persistence after one year of age requires consideration of a surgical release (Lloyd-Roberts and Fixsen 1990). When no definitive diagnosis can be made referral for an ophthalmic opinion may be appropriate.

Many ophthalmic conditions may produce a compensa- tory change in head posture, including paralytic and restrictive disorders of ocular movement, nystagmus and defects of the visual field (Kushner 1979; Mein and Trimble 1991; Pratt-Johnson and Tillson 1993). The most common ocular causes of torticollis in infancy are congenital paralytic squint and congenital nystagmus. Kraft, O'Donoghue and Roarty (1992) found that $74 \%$ of patients with unilateral paresis of the superior oblique muscle had abnormal head postures, $29 \%$ of patients with paresis of the lateral rectus muscle had a face turn, $68 \%$ of those with Duane's syndrome (a congenital condition simulating lateral rectus paresis) had a face turn, and all their patients with congenital nystagmus had a torticollis, with a face turn in $87 \%$. Kushner (1979) found underaction of the superior oblique muscle to be the most common ocular cause of torticollis in a series of 188 patients.

Patients with a paralytic squint adopt an abnormal head posture to maintain binocular vision and avoid diplopia. The exact mechanism depends on the affected muscle: the head may be placed so that the eyes are directed away from its field of action, thereby allowing ocular alignment to be maintained. Patients with paresis of a horizontally-acting extra-ocular muscle may achieve this with face turn alone, but a combination of face turn and chin elevation or depression may be necessary to correct for an abnormal vertically-acting muscle, and head tilt may also be found (Von Noorden 1990). Patients with nystagmus have a position of gaze in which the amplitude of the nystagmus is reduced, resulting in improved visual acuity.

Some ophthalmic papers (Von Noorden 1990; PrattJohnson and Tillson 1993) list features other than ocular pathology, which may help to distinguish ocular from nonocular torticollis, and we reviewed these in our patients. It has been suggested that ocular torticollis presents later than non-ocular, after head control and binocular vision have been established. In our series, however, two infants in the ocular group were noted to have abnormal head postures at birth and three in the non-ocular group had a relatively late onset, several months after birth. Thus, age at onset was not a useful distinguishing feature. As regards family history, nystagmus is frequently inherited and the patient in our series has X-linked recessive congenital nystagmus. Such a family history in a child with torticollis may be helpful, but other abnormalities of ocular motility are inherited in a complex multifactorial fashion, and are relatively common. A family history of these conditions is not predictive: three patients in our non-ocular group had a family history of ocular problems.

The range of neck movement should be of assistance since patients with ocular torticollis should have a full range; restriction would be expected in the non-ocular group. All 15 of our patients, however, had a normal range, although of the seven found to have a tight sternomastoid muscle at extreme rotation, only one also had an ocular problem. It also seems possible that long-standing torticollis of ocular origin may eventually produce secondary 


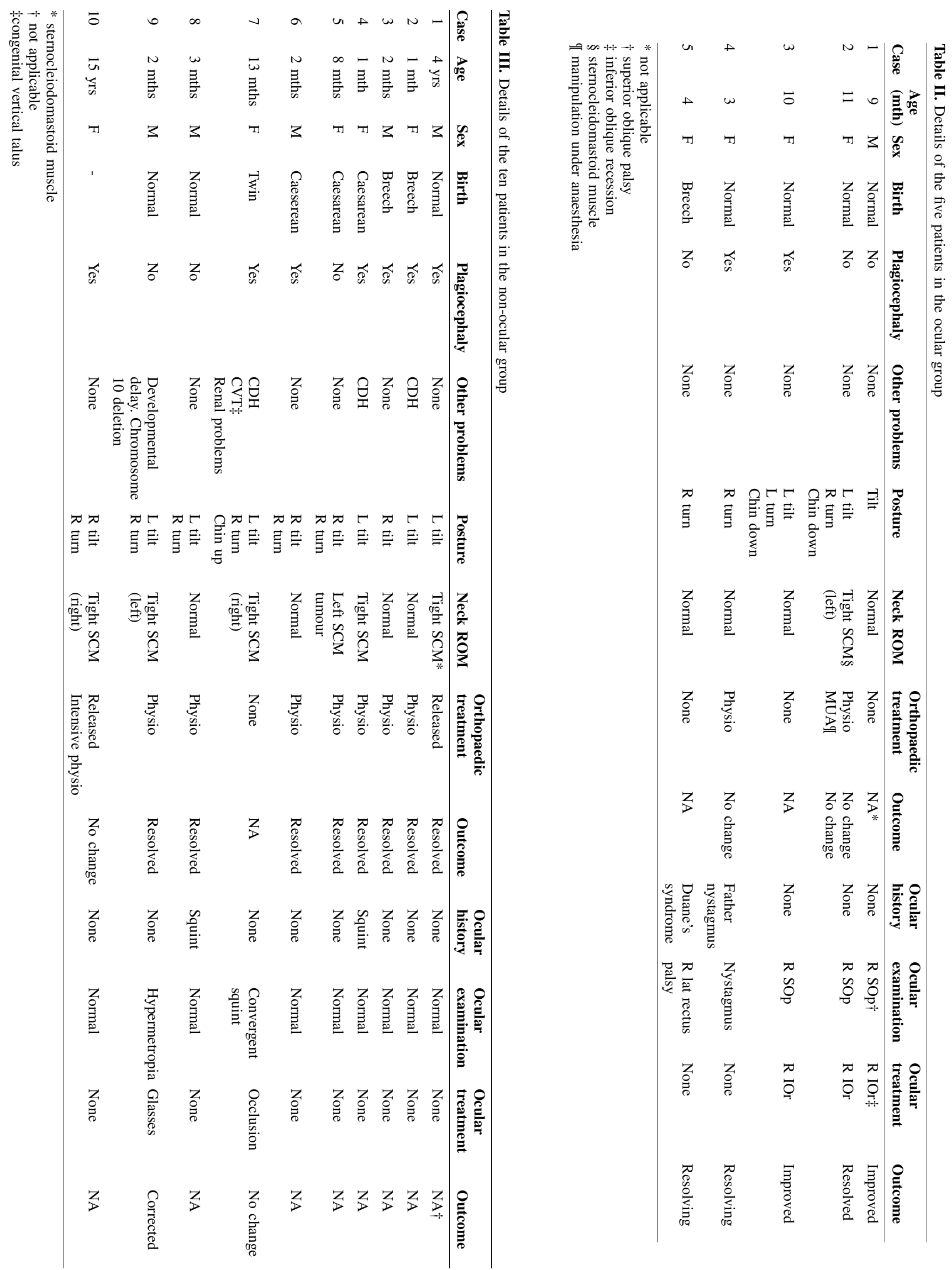


changes in the neck muscles. This means that ocular torticollis should be diagnosed as early as possible; in late cases it may persist even after treatment of the ocular defect, and even plagiocephaly secondary to torticollis has been reported in children with paresis of the superior oblique muscle (Saunders and Roberts 1995).

Occlusion of one eye may help to differentiate some ocular cases in patients in whom the torticollis is used to retain binocular vision. It removes the need for the posture, and the head should straighten. This will not work for longstanding torticollis with secondary neck changes, or when an ocular torticollis is for reasons other than maintaining binocular vision, and the test therefore has limited value.
We did not use it, and found no other factors predictive of an ocular cause. In our five cases the ocular pathology was subtle and was demonstrated only on detailed ophthalmic assessment.

Conclusions. Paralytic squint and nystagmus may lead to torticollis in children. This should be considered when orthopaedic examination fails to reveal a structural cause. We found no special features that predicted an ocular origin, and therefore recommend that all children with torticollis and no clear cause should be referred for ophthalmic assessment.

No benefits in any form have been received or will be received from a commercial party related directly or indirectly to the subject of this article.

\section{REFERENCES}

Fielding JW, Hawkins RJ. Atlanto-axial rotatory fixation (fixed rotatory subluxation of the atlanto-axial joint). J Bone Joint Surg [Am] 1977;59-A:37-44.

Hummer CD Jr, MacEwen GD. The coexistence of torticollis and congenital dysplasia of the hip. J Bone Joint Surg 1972;54-A: 1255-6.

Kahn ML, Davidson R, Drummond DS. Acquired torticollis in children. Orthop Rev 1991;20:667-74.

Kraft SP, O'Donoghue EP, Roarty JD. Improvement of compensatory head postures after strabismus surgery. Ophthalmology 1992;8: 1301-8.

Kushner BJ. Ocular causes of abnormal head postures. Ophthalmology 1979;86:2115-25.

Lloyd-Roberts GC, Fixsen JA. Orthopaedics in infancy and childhood. 2nd ed. London: Butterworth-Heinemann, 1990;92-3.
Lovell WW, Winter RB, eds. Pediatric orthopaedics. 2nd ed. Philadelphia, etc: JB Lippincott Co, 1986.

Mein J, Trimble R. Diagnosis and management of ocular motility disorders. 2nd ed. Oxford: Blackwell Scientific, 1991;10-11.

Phillips WA, Hensinger RN. The management of rotatory atlanto-axial subluxation in children. J Bone Joint Surg [Am] 1989;71-A:664-8.

Pratt-Johnson JA, Tillson G. Management of strabismus and amblyopia: a practical guide. New York: Thieme, 1993;239-41.

Saunders RA, Roberts EL. Abnormal head posture in patients with fourth cranial nerve palsy. Am Orthop J 1995;45:24-33.

Von Noorden GK. Binocular vision and ocular motility: theory and management of strabismus. 4th ed. St Louis: CV Mosby, 1990;369-72.

Weiner DS. Congenital dislocation of the hip associated with congenital muscular torticollis. Clin Orthop 1976;121:163-5. 